\title{
Differentiation of Mycobacterium tuberculosis complex from non-tubercular mycobacteria by nested multiplex PCR targeting IS6110, MTP40 and 32kD alpha antigen encoding gene fragments
}

Pallavi Sinha', Anamika Gupta', Pradyot Prakash', Shampa Anupurba ${ }^{1 *}$, Rajneesh Tripathi ${ }^{1}$ and G. N. Srivastava ${ }^{2}$

\begin{abstract}
Background: Control of the global burden of tuberculosis is obstructed due to lack of simple, rapid and cost effective diagnostic techniques that can be used in resource poor-settings.

To facilitate the early diagnosis of TB directly from clinical specimens, we have standardized and validated the use of nested multiplex PCR, targeting gene fragments 156110 , MTP40 and 32kD a-antigen encoding genes specific for Mycobacterium tuberculosis complex and non-tubercular mycobacteria (NTM), in comparison to smear microscopy, solid culture and single step multiplex PCR. The results were evaluated in comparison to a composite reference standard (CRS) comprising of microbiological results (smear and culture), clinical, radiological and cytopathological findings, clinical treatment and response to anti-tubercular therapy.
\end{abstract}

Methods: The nested multiplex PCR (nMPCR) assay was evaluated to test its utility in 600 (535 pulmonary and 65 extra-pulmonary specimens) clinically suspected TB cases. All specimens were processed for smear, culture, single step multiplex PCR and nested multiplex PCR testing.

Results: Out of 535 screened pulmonary and 65 extra-pulmonary specimens, 329 (61.5\%) and 19 (29.2 \%) cases were culture positive for M. tuberculosis. Based on CRS, 450 patients had "clinical TB" (definitive-TB, probable-TB and possible-TB). Remaining 150 were confirmed "non-TB" cases. For culture, the sensitivity was low, $79.3 \%$ for pulmonary and $54.3 \%$ for extra-pulmonary cases. The sensitivity and specificity results for nMPCR test were evaluated taken composite reference standard as a gold standard. The sensitivity of the nMPCR assay was $97.1 \%$ for pulmonary and $91.4 \%$ for extra-pulmonary TB cases with specificity of $100 \%$ and $93.3 \%$ respectively.

Conclusion: Nested multiplex PCR using three gene primers is a rapid, reliable and highly sensitive and specific diagnostic technique for the detection and differentiation of $M$. tuberculosis complex from NTM genome and will be useful in diagnosing paucibacillary samples. Nested multiplex PCR assay was found to be better than single step multiplex PCR for assessing the diagnosis of TB.

Keywords: Mycobacterium tuberculosis complex, Non-tubercular mycobacteria, Nested multiplex PCR, Composite reference standard

\footnotetext{
* Correspondence: shampa_anupurba@yahoo.co.in

'Department of Microbiology, Institute of Medical Sciences, Banaras Hindu

University, 221005 Varanasi, India

Full list of author information is available at the end of the article
} 


\section{Background}

Tuberculosis (TB), caused by Mycobacterium tuberculosis complex (MTBC), still remains the major killer disease worldwide, especially in developing countries in spite of considerable progress in diagnosis and treatment [1]. Mycobacterium tuberculosis complex comprises of Mycobacterium tuberculosis (MTB), M. africanum, $M$. canettii, M. bovis, M. microti, M. orygis, M. caprae, $M$. pinnipedii, $M$. suricattae and recently recognized $M$. mungi [2]. According to WHO there were approximately 9.0 million new cases and 1.5 million deaths globally in 2014. India contributed the highest number of new cases of TB, accounting for $24 \%$ of the global burden [1]. Extra-pulmonary tuberculosis (EPTB) contributes about $15-20 \%$ of the total cases of tuberculosis worldwide [1]. A major obstacle to the diagnosis of EPTB is the atypical presentation, often simulating neoplasia and/or inflammatory disorders.

The non-tuberculous mycobacterial (NTM) infections have also increased in many regions of the world along with MTBC infections and much of this increase in the burden of TB concurred with human immune deficiency virus (HIV) infection in patients [3, 4]. The species of NTM associated with human disease are: $M$. avium, $M$. intracellulare, M. kansasii, M. fortuitum, M. chelonae, M. szulgai, M. paratuberculosis, M. scrofulaceum etc. Most of the incidence of NTM infections has been reported from TB non-endemic countries and rarely from TB endemic countries because the chances of missing NTM infection are higher in TB endemic countries $[5,6]$.

The current standard of care for diagnostic techniques does not include bacterial characterization. Consequently, some NTM cases with positive smears will continue to be misclassified as MTB and receive chemotherapy commonly used for tuberculosis due to which some of the NTM strains may be resistant. Hence, majority of NTM infections will remain undetected. In addition, cases of mixed infection have also been reported $[4,7]$.

The conventional methods such as smear microscopy has low sensitivity and specificity and culture is time consuming (6-8 weeks) because of the slow growth rate of TB bacilli [7-9]. To overcome these problems, nucleic acid amplification test (NAAT) has been used for diagnosis of pulmonary tuberculosis (PTB) and extra-pulmonary tuberculosis [10]. In case of extra-pulmonary specimens there is a lack of sensitivity of conventional PCR techniques as they are mostly paucibacillary in nature. Another major limitation of single step PCR for pulmonary and extra-pulmonary specimens is the presence of PCR inhibitors that inhibit the amplification based techniques. Therefore, a two step process is necessary to eliminate/dilute the inhibitors present in the clinical specimens.

The target sequences IS6110 and MTP4O have been used in multiplex PCR for the diagnosis of pulmonary and extra-pulmonary TB which increases the sensitivity for detection [11-15]. One study has reported a robust, reproducible and uniform nested PCR (nPCR) protocol for the removal of PCR inhibitors, but nested PCR lacks the specificity by using single target sequence [16]. Some studies have also compared nucleic acid amplification test with composite reference standard (CRS) and culture [17-19], but these techniques could not differentiate MTBC from NTM. Therefore, we have used nested multiplex PCR (nMPCR) assay and compared it with composite reference standard and single step multiplex PCR (mPCR) assay to evaluate the true diagnostic potential of the nMPCR assay for pulmonary and extrapulmonary TB. The CRS for this study comprised of signs, symptoms, radiological scans, cytolopathology, microbiological results (smear and LJ culture), previous and family history and response to anti-tubercular therapy (ATT).

\section{Methods \\ Study design}

This study was conducted during the period May 2012 February 2014 at the Department of Microbiology, Institute of Medical Sciences, Banaras Hindu University, Varanasi, India. The patients registered in this study were attending either outpatient department or were admitted in the ward, Department of Chest and Respiratory diseases, Sir Sunder Lal Hospital, Institute of Medical Sciences, Banaras Hindu University.

\section{Specimen collection}

A total of 600 clinical specimens were studied, including 535 pulmonary [523 sputum and 12 Bronchoalveolar Lavage (BAL)] and 65 extra-pulmonary specimens from outpatients and inpatients of a tertiary care centre of Banaras Hindu University, Varanasi. The 65 extrapulmonary specimens included 15 sterile body fluids (5 pleural fluid, 9 cerebrospinal fluid (CSF) and one blood from bone marrow), 15 pus samples, 20 urine samples and 15 fine needle aspirates (FNAs). Each sample was divided into two parts. First part was used for microbiological investigations (microscopy and culture) and second part was processed for PCR.

\section{Clinical assessment of patients}

The patients were categorized on the basis of composite reference standard criteria.

(A) Definitive TB groups: AFB smear positive and culture positive $(\mathrm{S}+\mathrm{C}+)$ and AFB smear negative and culture positive $(\mathrm{S}-\mathrm{C}+)$,

(B) Probable TB groups: Patients' selection with AFB smear positive and culture negative $(\mathrm{S}+\mathrm{C}$-) but showing clinical symptoms, chest $\mathrm{X}$-ray highly indicative of TB and/or cytology suggestive of TB, 
(C) Possible TB groups: smear negative and culture negative ( $\mathrm{S}-\mathrm{C}-$ ) and only clinical signs and/or symptoms suggestive of TB; patients response to ATT and

(D) Non-TB groups: microbiological tests for TB were negative and patient improved without taking ATT but two specimens were obtained from patients with lymphadenopathy and metastatic carcinoma.

\section{Sample preparation}

Sputum, pus and BAL (bronchoalveolar Lavage) samples were processed using Petroff's method (4\% $\mathrm{NaOH}$ ) [20]. One loopful (approximately $0.1-0.15 \mathrm{ml}$ ) of sterile body fluids like pleural fluid, CSF and blood from bone marrow were inoculated directly on Lowenstein Jensen (LJ) medium. If the specimen volume was more than $10 \mathrm{ml}$, concentration by centrifugation was done at about $3000-3500 \times \mathrm{g}$ for $15-20 \mathrm{~min}$ [21, 22]. FNAC samples were collected aseptically, dispensed in $200 \mu \mathrm{l}$ phosphate buffer saline and one loopful was directly inoculated on LJ medium. Urine samples were concentrated by centrifugation at $3000 \times \mathrm{g}$ for $15 \mathrm{~min}$ followed by decontamination in a similar manner as sputum [22].

\section{Microscopy and culture}

All pulmonary and extra pulmonary clinical specimens and the sediments were subjected to smear examination through the standard Ziehl Neelsen's staining method and were cultured onto a pair of Lowenstein-Jensen slants [23]. The LJ slants were incubated at $37{ }^{\circ} \mathrm{C}$ and inspected weekly for mycobacterial growth for a period of 8 weeks. Cultures grown were identified by standard biochemical tests such as nitrate reductase, heat stable catalase and sensitivity to PNB $[24,25]$.

\section{DNA extraction}

DNA extraction was carried out from the processed clinical specimens by CTAB-chloroform method [26]. The concentration of DNA was determined by measuring the optical density at $260 \mathrm{~nm}$ by Nanodrop 2000 (Thermo scientific, US). DNA used for PCRs were diluted in Tris-EDTA buffer (pH-7.8) to final concentrations of less than $40 \mu \mathrm{g} / \mathrm{ml}$ to overcome the action of potential PCR inhibitors.

\section{Two step nested multiplex PCR standardization for the IS6110, MTP40 and 32-kDa-antigen encoding gene sequences}

Two step nested multiplex PCR assay was standardized and was found to have quantitative sensitivity to detect the DNA equivalent to 1-2 organisms. It tested positive with standard strain of $M$. tuberculosis, H37Rv. In each independent $\mathrm{nMPCR}$ assay, test results were compared with the results for one positive and one negative control. We used the reference strain H37Rv M. tuberculosis as positive control and molecular grade water (no target DNA) as negative control. M. tuberculosis $\mathrm{H} 37 \mathrm{Rv}$ and M. smegmatis standard strain had been obtained from JALMA, Agra, India.

The identification and differentiation of MTBC from NTM was carried out by using specific pair of primers reported by Portillo et al. [27] to amplify IS6110, MTP40 $\mathcal{E} 32 k D$ a-antigen encoding gene sequences (Table 1) specific for $M$. tuberculosis complex, M. tuberculosis and non-tuberculous mycobacteria respectively in single step multiplex PCR. In nested multiplex PCR we have designed specific pair of primers for amplification of IS6110, MTP40 \& 32kD $\alpha$-antigen encoding gene sequences which gave band sizes of $500 \mathrm{bp}, 342 \mathrm{bp} \& 413 \mathrm{bp}$ respectively (Table 2).

The first round PCR master mix was prepared by mixing $24 \mu \mathrm{l}$ of a previously mixed reaction mixture [containing $2.5 \mu \mathrm{l}$ of $10 \mathrm{X}$ reaction buffer (GeNei, Banglore, India), $2.5 \mu \mathrm{l}$ of $200 \mu \mathrm{M}$ concentrations of each of the deoxynucleoside triphosphates (dNTPs) (GeNei, Banglore, India), $0.1 \mu \mathrm{l}$ of $5 \mathrm{U}$ Taq DNA Polymerase (GeNei, Banglore, India) and $1 \mu$ l of the each oligonucleotide primers (10 pmol) (GeNei, Banglore, India)], $5 \mu \mathrm{l}$ of the DNA template and added milli Q to create a total volume of $25 \mu \mathrm{l}$. The first-round amplification was carried out in a thermocycler (T-100 ${ }^{\mathrm{Tm}}$-Bio-Rad) under the following conditions: initial denaturation at $95{ }^{\circ} \mathrm{C}$ for $3 \mathrm{~min}$,

Table 1 Sequences of primers used in the detection of Mycobacterium spp. in single step multiplex PCR assay

\begin{tabular}{|c|c|c|c|c|}
\hline Genes & Primers & Sequence $\left(5^{\prime}-3^{\prime}\right)$ & Size (bp) & Reference \\
\hline \multirow[t]{2}{*}{ MTP40a } & MTB F & CGGCAACGCGCCGTCGGTGG & 396 & Herrera E. A. 1996 [15] \\
\hline & MTB R & CCCCCCACGGCACCGCCGGG & & \\
\hline \multirow[t]{2}{*}{$156110^{\mathrm{b}}$} & MTBC F & CGGAGACGGTGCGTAAGTGG & 984 & Wojciech, 1992 [39] \\
\hline & MTBC R & GATGGACCGCCAGGGCTTGC & & \\
\hline \multirow[t]{2}{*}{$32 k D$ a-antigen ${ }^{c}$} & NTM F & TTCCTGACCAGCGAGCTGCCG & 506 & Ohara et al., 1993 [40] \\
\hline & NTM R & CCCCAGTACTCCCAGCTGTGC & & \\
\hline
\end{tabular}

aspecific for Mycobacterium tuberculosis

b specific for Mycobacterium tuberculosis complex

cspecific for non-tuberculous mycobacterium 
Table 2 Sequences of primers used in nested multiplex PCR for the detection of Mycobacterium spp.

\begin{tabular}{|c|c|c|c|c|}
\hline Genes & Primers & Sequence $\left(5^{\prime}-3^{\prime}\right)$ & Size (bp) & Reference (Primers) \\
\hline \multirow[t]{2}{*}{$\overline{n M T P 40^{\mathrm{a}}}$} & MTB2F & CGTTCGGGATGCACTGCG & 342 & In this study \\
\hline & MTB2R & CACCCGGCGAATTCGTCAC & & \\
\hline \multirow[t]{2}{*}{$n / S 6110^{b}$} & MTBC2F & CGATCGCCCCATCGACCTACT & 500 & In this study \\
\hline & MTBC2R & GGTCGAGTACGCCTTCTTGT & & \\
\hline \multirow[t]{2}{*}{$n 32 k D$ a-antigen ${ }^{c}$} & NTM2F & CACCCGCAGTTCATCTA & 413 & In this study \\
\hline & NTM2R & CGTTGTAGGCGTCCTGG & & \\
\hline
\end{tabular}

$n$ Primers used in nested PCR

${ }^{\mathrm{a}}$ specific for Mycobacterium tuberculosis

b specific for Mycobacterium tuberculosis complex

cspecific for non-tuberculous mycobacterium

35 cycles of $94{ }^{\circ} \mathrm{C}$ for $1 \mathrm{~min}, 65^{\circ} \mathrm{C}$ for $1 \mathrm{~min}$ and $72{ }^{\circ} \mathrm{C}$ for $50 \mathrm{~s}$ and a final extension at $72{ }^{\circ} \mathrm{C}$ for $7 \mathrm{~min}$. In nested multiplex PCR, reaction mixture was same as that in first round PCR, except it contained $15 \mathrm{pmol}$ of second round primers (Table 2) and $2 \mu$ l of 1:6 diluted product of the primary cycle as DNA template. The amplification conditions were identical to that of first round PCR. The amplified products of both cycles were analyzed by agarose gel electrophoresis (GeNei, Banglore, India) on $2 \%$ agarose gel (GeNei, Banglore, India) using $5 \mu \mathrm{l}$ of amplified products. The gels were stained with ethidium bromide $(0.5 \mu \mathrm{g} / \mathrm{ml})$ and bands were visualized under UV light.

\section{Statistical analysis}

Sensitivity, specificity, positive predictive value and negative predictive value of the nMPCR were evaluated by using online MedCalc and compared with single step PCR, microbiological tests and CRS.

\section{Ethics statement}

This study has been ethically approved by the ethical committee of the Institute of Medical Sciences, Banaras Hindu University, Varanasi, India.

\section{Results}

\section{Clinical data}

Out of 600 patients 223 (37.2\%) were females and 377 (62.8\%) were males. The participants ranged from 2 to 90 years (median age $26.3 \pm 16.8$ ). Most of the patients [267/600; (44.5\%) were in $20-40$ years age group.

\section{Patient categories}

A total of 600 patients were considered in this study. Out of these participants, $348(58.0 \%)$ were culture positive "definitive TB" cases [255 (42.5\%) being smear positive and 93 (15.5\%) being smear negative]; 47 (7.8\%) were clinically, radiologically, and/or cytologically positive, suggestive of "probable TB" cases; 55 (9.2\%) were only clinically positive and responded to ATT, suggestive of "possible TB" cases; and 150 (25\%) patients had no evidence of TB and were "non-TB" cases.
Details of study participations are depicted in Fig. 1 of 450 specimens, $92.2 \%(n=415)$ pulmonary and $7.8 \%$ $(n=35)$ extra-pulmonary specimens were able to fit the CRS criteria as reference.

\section{Culture and microscopy}

Out of 535 pulmonary samples, $53.6 \%(n=287)$ were positive for AFB bacilli whereas $61.5 \%(n=329)$ samples were positive for MTB culture. Of the 65 extra-pulmonary specimens $3.1 \%(n=2)$ pleural fluid, $4.6 \%(n=3)$ CSF, $9.2 \%(n=6)$ pus and $6.1 \%(n=4)$ FNAs were positive by Ziehl-Neelsen staining, while $4.6 \%(n=3)$ pleural fluid, $6.1 \%(n=4)$ CSF, $1.5 \%(n=1)$ bone marrow, $10.8 \%(n=7)$ pus and $6.1 \%(n=4)$ FNAs were culture positive (Table 3). From 600 specimens, $50.3 \%(302 / 600)$ were AFB smear positive, 344 (57.3 \%) were $M$. tuberculosis culture positive, 4 (0.7 \%) were NTM positive and 241 (40.2 \%) were culture negative. Eleven (1.8 \%) were contaminated. Finally 348 specimens were mycobacteria culture positive which was considered in the final analysis.

\section{Evaluation of nested multiplex PCR}

The results obtained by $\mathrm{nMPCR}$ for pulmonary and extrapulmonary specimens are shown in Table 3 . On subjecting all the clinical specimens to nMPCR, $75.3 \%(403 / 535)$ pulmonary and $49.2 \%$ (32/65) extra-pulmonary samples were positive for either or all the target genes namely IS6110, MTP40 and $32 k D-\alpha$ antigen. The gel picture is shown in Fig. 2. Further, detection of TB increased from $60.8 \%(365 / 600)$ by single step mPCR to $72.5 \%(435 / 600)$ by $\mathrm{nMPCR}$ for clinical specimens. In addition, with regard to PCR target detection in the nested multiplex PCR protocol, $87.8 \%$ [including $69.7 \%$ (373/535) pulmonary and $33.8 \%(22 / 65)$ extra-pulmonary specimens] of the 450 clinically confirmed and suspected TB cases showed both IS6110 and MTP40 amplified bands patterns which belongs to the MTBC and MTB. Further, $1.1 \%(6 / 535)$ pulmonary and $1.5 \%(1 / 65)$ extra-pulmonary (pus) samples were positive for MTP4O and $32 k D$-antigen encoding gene (mixed infection) and $0.8 \%(4 / 450)$ cases were positive for $32 k D \alpha$-antigen encoding gene, 


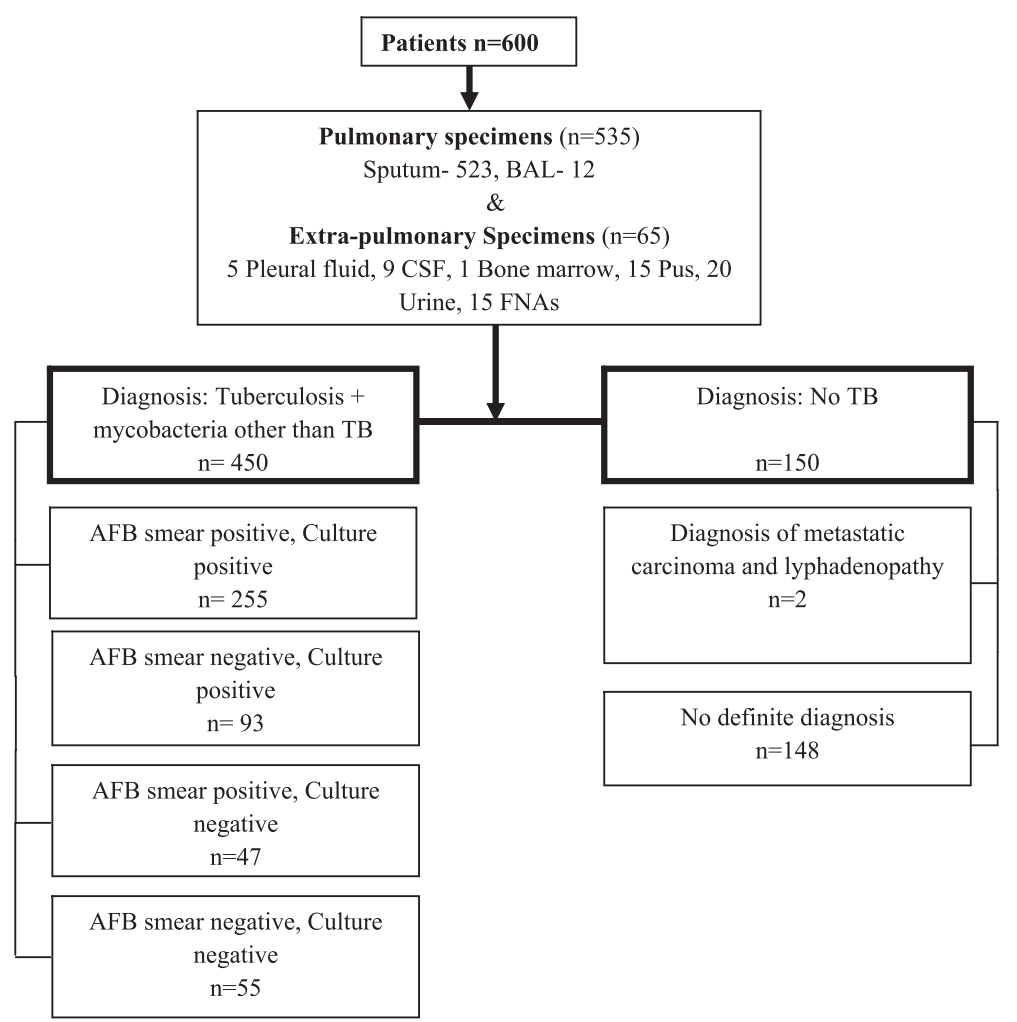

Fig. 1 Flow chart of the participants included and analyzed in this study

IS6110 and MTP4O (mixed infection) (Fig. 3). No individual sample was established by culture to harbour both $M$. tuberculosis and non tubercular mycobacteria, as was seen with samples examined by the nMPCR assay. Among 450 TB cases, only IS6110 band pattern was detected in $1.5 \%(n=7)$ samples including 4 sputum, 1 BAL, 1 pus and 1 FNA and only MTP40 band was detected in $2.0 \%(n=9)$ samples including 7 sputum, 1 CSF and 1 pus. Only $32 k D \alpha$-antigen encoding gene band pattern was obtained in $2.9 \%(13 / 450)$ specimens.

Of the 150 samples (control), from those patients without mycobacterial infections, $98.7 \%(n=148)$ samples were found to be nested multiplex PCR negative, as expected; whereas, remaining $1.3 \%(n=2)$ samples were positive for both IS6110 and MTP4O band patterns (Table 3).

\section{Diagnostic association of nMPCR results with composite reference standard criteria}

Table 4 represent the association of $\mathrm{nMPCR}$ and single step $\mathrm{mPCR}$ with CRS in clinical specimens. Among the $\mathrm{S}+\mathrm{C}+$ specimens (Group A), single step $\mathrm{mPCR}$ and nMPCR assay detected mycobacterial DNA in $92.9 \%$ (237/255) and $100 \%(255 / 255)$ of specimens respectively. Among the S-C+ specimens (Group A), $77.4 \%(72 / 93)$ specimens were single step mPCR positive and $98.9 \%$
(92/93) were positive for nMPCR assay. From this group $8.6 \%(22 / 255)$ and $15.3 \%(39 / 255)$ of the samples were single step MPCR positive for only MTP4O and IS6110 band patterns but in nMPCR only $3.5 \%$ (9/255) and $2.3 \%$ $(6 / 255)$ of the specimens were positive for only MTP40 and $I S 6110$ respectively (Additional file 1 ).

Out of $47 \mathrm{~S}+\mathrm{C}$ - specimens (Group B) $66.0 \%(n=31)$ were single step mPCR positive and $95.7 \%(n=45)$ were positive for nMPCR. On the other hand, $45.4 \%(25 / 55)$ and $78.2 \%(43 / 55)$ of the S-C-specimens were positive for single step PCR and nMPCR assay respectively (Table 4). There details for specific band patterns are shown in additional file 1 . Finally, out of 150 samples taken from patients without mycobacterial infection, 148 (included in Group D) were found to be negative for both single step $\mathrm{MPCR}$ and $\mathrm{nMPCR}$ whereas, remaining $2(1.3 \%)$ samples were positive for nMPCR assay but negative in single step mPCR.

There were 9 samples in group A which showed absence of IS6110 and presence of MTP4O band pattern in nMPCR assay indicating presence of M. tuberculosis strains lacking IS6110 gene sequence. Besides, some specimens from group A and B showed presence of members of MTBC other than $M$. tuberculosis (Additional file 1). 
Table 3 Comparison of smear, culture, single step mPCR and nMPCR for detection of Mycobacterium spp. in clinical samples

\begin{tabular}{|c|c|c|c|c|c|c|c|c|c|c|c|c|}
\hline Nature of samples & $\begin{array}{l}\text { No. } \\
\text { of cases }\end{array}$ & $\begin{array}{l}\text { CRS positive } \\
\text { cases }\end{array}$ & $\begin{array}{l}\text { Z-N smear } \\
(\%)\end{array}$ & $\begin{array}{l}\text { Culture } \\
(\%)\end{array}$ & $\begin{array}{l}\text { Single step mPCR } \\
(\%)\end{array}$ & $\begin{array}{l}\mathrm{nMPCR} \\
(\%)\end{array}$ & $\begin{array}{l}\text { IS6110 \& MTP40 } \\
(\%)\end{array}$ & $\begin{array}{l}\text { MTP40 \& 32kD } \\
\text { a-antigen }\end{array}$ & $\begin{array}{l}\text { Only } 156110 \\
(\%)\end{array}$ & $\begin{array}{l}\text { Only MTP40 } \\
(\%)\end{array}$ & $\begin{array}{l}\text { Only 32kD } \\
\text { a-antigen (\%) }\end{array}$ & $\begin{array}{l}156110+\text { MTP40 } \\
+32 \mathrm{kD} \text { a-antigen }\end{array}$ \\
\hline Pulmonary samples & 535 & 415 (77.6) & $287(53.6)$ & $\begin{array}{l}329 \\
(61.5)\end{array}$ & $345(64.5)$ & $\begin{array}{l}403 \\
(75.3)\end{array}$ & $373(69.7)$ & $6(1.1)$ & $5(0.9)$ & $7(1.3)$ & $9(1.7)$ & $3(0.6)$ \\
\hline Sputum & 523 & $409(78.2)$ & $283(53.3)$ & $\begin{array}{l}323 \\
(61.7)\end{array}$ & $337(64.4)$ & $\begin{array}{l}394 \\
(75.3)\end{array}$ & $365(69.8)$ & $6(1.1)$ & $4(0.8)$ & $7(1.3)$ & $9(1.7)$ & $3(0.6)$ \\
\hline BAL & 12 & $6(50)$ & $4(33.3)$ & $6(50)$ & $8(66.6)$ & $9(75)$ & $8(66.6)$ & 0 & $1(0.2)$ & 0 & 0 & 0 \\
\hline $\begin{array}{l}\text { Extra-pulmonary } \\
\text { samples }\end{array}$ & 65 & $35(53.8)$ & $15(23.1)$ & $19(29.2)$ & $20(30.8)$ & $32(49.2)$ & $22(33.8)$ & $1(1.5)$ & $2(3.0)$ & $2(3.0)$ & $4(6.1)$ & $1(1.5)$ \\
\hline Pleural Fluid & 5 & $3(60)$ & $2(40)$ & $3(60)$ & $3(60)$ & $3(60)$ & $3(60)$ & 1 & 0 & 0 & 0 & 0 \\
\hline CSF & 9 & $6(66.7)$ & $3(33.3)$ & $4(44.4)$ & $4(44.4)$ & $5(55.5)$ & $4(44.4)$ & 0 & 0 & $1(11.1)$ & 0 & 0 \\
\hline Bone marrow & 1 & $1(100)$ & 0 & $1(100)$ & $1(100)$ & $1(100)$ & $1(100)$ & 0 & 0 & 0 & 0 & 0 \\
\hline Pus & 15 & $12(80)$ & $6(40)$ & $7(46.7)$ & $6(40)$ & $12(80)$ & $7(46.7)$ & $1(6.7)$ & $1(6.7)$ & $1(6.7)$ & $1(6.7)$ & $1(6.7)$ \\
\hline Urine & 20 & $4(20)$ & 0 & 0 & $1(5)$ & $3(15)$ & $3(15)$ & 0 & 0 & 0 & 0 & 0 \\
\hline FNAs & 15 & $9(60)$ & $4(26.7)$ & $4(26.7)$ & $5(33.3)$ & $8(53.3)$ & $4(26.7)$ & 0 & $1(6.7)$ & 0 & $3(20)$ & 0 \\
\hline Total & & 450 & $302(67.1)$ & $\begin{array}{l}348 \\
(77.3)\end{array}$ & $365(81.1)$ & $\begin{array}{l}435 \\
(96.7)\end{array}$ & $395(87.8)$ & $7(1.5)$ & $7(1.5)$ & $9(2.0)$ & $13(2.9)$ & $4(1.0)$ \\
\hline Control & 150 & 0 & - & - & - & $2(1.3)$ & $2(1.3)$ & - & - & - & - & - \\
\hline Total & 600 & - & - & - & - & $\begin{array}{l}437 \\
(72.8)\end{array}$ & $397(66.2)$ & - & - & - & - & - \\
\hline
\end{tabular}

BAL bronchoalveolar lavage, CSF cerebrospinal fluid, FNAs fine needle aspirates, $m P C R$ multiplex $P C R, n M P C R$ nested multiplex PCR 


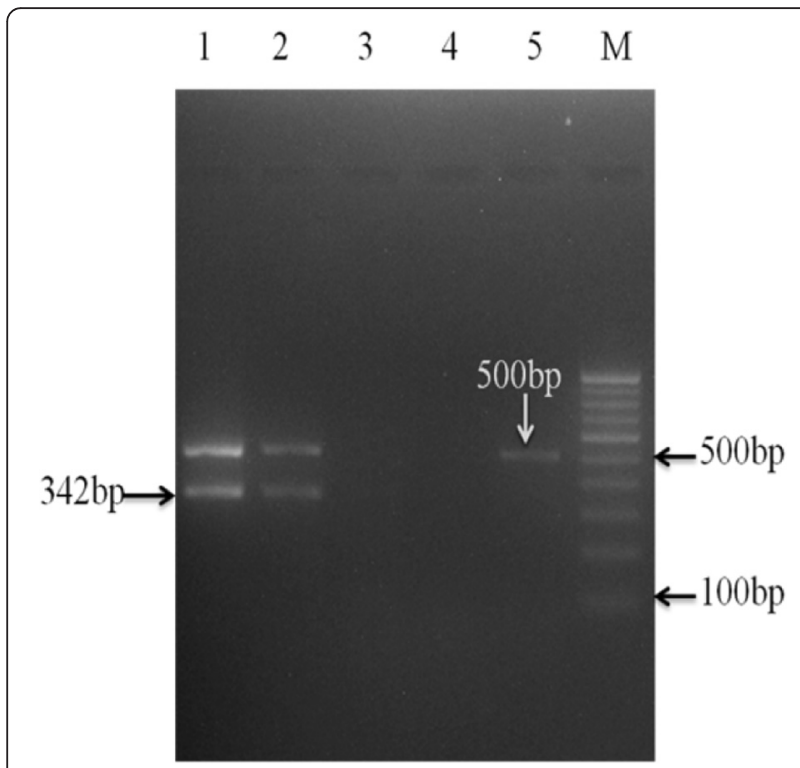

Fig. 2 Agarose gel electrophoresis of nested multiplex PCR for the identification of Mycobacterium tuberculosis complex from clinical samples. Lane-1: positive control (H37Rv); lane-2: clinical samples positive for 156110 and MTP40; Lane-3- negative control (MQ water); Lane-4- negative clinical sample; lane-5- patient samples positive for only 156110and negative for MTP40

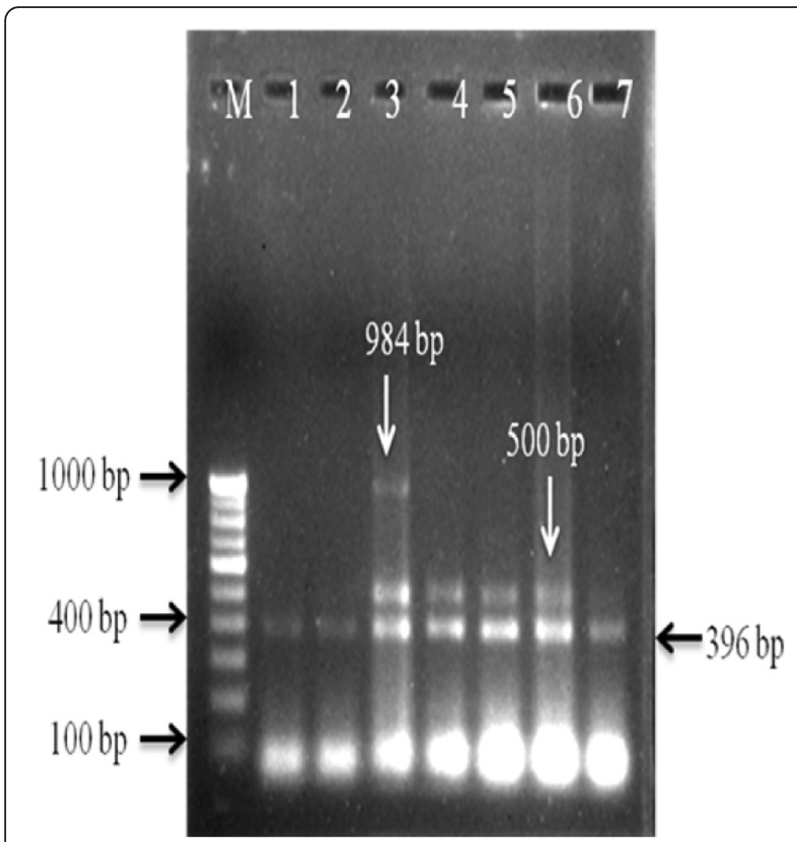

Fig. 3 Agarose gel electrophoresis showing mixed infection in single step multiplex PCR. M- 100 bp DNA marker; lane-1, 2: clinical samples positive for MTP40; lane-3: clinical sample positive for MTP40, 156110 and 32kD alpha antigen (Mixed infection); lane- 4, 5, 6 \& 7: clinical samples positive for MTP40 and IS6110

\section{Sensitivity and specificity}

Performance of all tests using CRS as a gold standard for all clinical specimens are presented in Table 5. As can be seen, nMPCR test have higher sensitivity than smear, culture and single step mPCR in different clinical samples. The sensitivities of smear, culture, single step PCR, nMPCR tests and CRS were found to be 69.2, 79.3, 83.1, 97.1 and $100 \%$ for PTB and 42.9, 54.3, 57.1, 91.4 and $100 \%$ for EPTB cases.

\section{Discussion}

Early identification of the infecting microorganism is necessary for patient management. In the case of MTB infection, rapid diagnosis and identification is a major factor for starting anti-TB drug therapy and to control the dissemination of MTB bacilli from person to person. Further, it is necessary to differentiate MTBC members from NTM for proper management of tuberculosis. The precise and early diagnosis of extra-pulmonary TB is challenging due to the paucibacillary nature of the specimens and requiring long incubation time for growth of tubercle bacilli. This long delay without positive or negative microbiological results could be shortened by the use of amplification techniques. However, these methods have relatively low sensitivity when applied directly to extra-pulmonary samples [28].

Therefore, we evaluated the utility of nested multiplex PCR protocol for paucibacillary pulmonary and extrapulmonary specimens. The test detected mycobacterial DNA in $99.7 \%(347 / 348)$ specimens of 'confirmed TB' cases, including $26.4 \%(92 / 348)$ of smear negative TB cases. It was also observed that nMPCR protocol detected mycobacterial DNA in $95.7 \%$ (45/47) of the samples from 'probable TB' cases, whose culture were negative but who had positive radiological tests and/or positive cytolopathology reports. Whereas, $78.2 \%(43 / 55)$ of the samples, whose smear and culture were negative from 'possible TB' cases but patients under ATT shedding non-cultivable bacteria also detected by nMPCR. It has been reported that nested PCR could detect those mycobacteria that are non- cultivable [29]. One hundred forty eight samples (non-TB cases) from patients without mycobacterial infections were negative for CRS criteria and nMPCR assay. It means these patients were considered as truly negative for TB infection. Whereas, remaining two samples from patients with metastatic carcinoma and lymphadenopathy, who had no clinical symptoms of TB may be false- positive result by nMPCR. The immunosuppressive nature of a malignant lesion may have been capable of reactivating a latent tubercular infection; hence, there may be coexistence of malignancy and tuberculosis.

A previous study has reported highest PCR positivity rates for pulmonary (77 \%) and extra-pulmonary (11 \%) 
Table 4 Comparison of conventional procedures with single step mPCR and nested multiplex PCR for detection of Mycobacterium spp. in different groups of clinical specimens

\begin{tabular}{|c|c|c|c|c|}
\hline Type & Study group & No. of patients $(n=600)$ & Single-step mPCR (\%) & Nested multiplex PCR (\%) \\
\hline \multirow[t]{3}{*}{ Group A } & Definitive TB group $(N=348)$ & & & \\
\hline & AFB smear + ve Culture + ve & $255(42.5)$ & $237(92.9)$ & $255(100)$ \\
\hline & AFB smear -ve Culture + ve & $93(15.5)$ & $72(77.4)$ & $92(98.9)$ \\
\hline \multirow[t]{2}{*}{ Group B } & Probable TB group $(N=47)$ & & & \\
\hline & AFB smear + ve Culture -ve & $47(7.8)$ & $31(66.0)$ & $45(95.7)$ \\
\hline \multirow[t]{2}{*}{ Group C } & Possible TB group $(N=55)$ & & & \\
\hline & AFB smear -ve Culture -ve & $55(9.2)$ & $25(45.4)$ & $43(78.2)$ \\
\hline Group D & Non-TB group $(N=150)$ & $150(25)$ & 0 & $2(1.3)$ \\
\hline Total & & 600 & $365(60.8)$ & $437(72.8)$ \\
\hline
\end{tabular}

+ve positive, -ve negative

samples using IS6110 as a specific target sequence [30]. However in some parts of the world, few strains do not possess the IS6110 target sequence in their genome, which may cause a false negative result and thereby decrease the sensitivity of the assay [31,32]. Recently, one study has reported $41.6 \%$ and $36 \%$ PCR positivity by multiplex PCR targeting MTP40 and IS6110 respectively [11]. Although, some studies have standardized the nested PCR assay to detect even single bacillus in clinical samples which have increased the sensitivity for detection of MTB, nested PCR using single target alone could not differentiate members of MTBC from non-tubercular mycobacteria $[33,34]$. Therefore, in this study we have used more than two target sequences in $\mathrm{nMPCR}$ assay, which increased the positivity $(72.8 \%)$ for detection of mycobacterial DNA. Mixed infection of NTM and Mycobacterium tuberculosis was found in $0.2 \%$ cases by Aliyu et al. [7]. We have found that $2.4 \%(11 / 450)$ cases are shown mixed infection of NTM and MTBC. Higher positivity of nMPCR might be due to its ability to detect less amount of target DNA (1 bacilli/ $\mu$ l) directly from clinical samples even in the presence of relatively large amount of human

Table 5 Sensitivity and specificity of conventional methods, nMPCR assay and CRS with respect to different specimens

\begin{tabular}{|c|c|c|c|c|c|c|c|c|}
\hline Different testes & Test results & TB group & Control $(n=150)$ & Sensitivity (\%) & Specificity (\%) & PPV (\%) & NPV (\%) & $\mathrm{Cl}$ \\
\hline \multicolumn{9}{|c|}{ Pulmonary TB $(n=535)$} \\
\hline AFB smear & $\begin{array}{l}\text { Positive } \\
\text { Negative }\end{array}$ & $\begin{array}{l}287 \\
128\end{array}$ & $\begin{array}{l}0 \\
120\end{array}$ & 69.2 & 100 & 100 & 48.4 & $64.5 \%-73.6 \%$ \\
\hline Culture & $\begin{array}{l}\text { Positive } \\
\text { Negative }\end{array}$ & $\begin{array}{l}329 \\
86\end{array}$ & $\begin{array}{l}0 \\
120\end{array}$ & 79.3 & 100 & 100 & 58.2 & $75.0 \%-83.1 \%$ \\
\hline Single step mPCR & $\begin{array}{l}\text { Positive } \\
\text { Negative }\end{array}$ & $\begin{array}{l}345 \\
70\end{array}$ & $\begin{array}{l}0 \\
120\end{array}$ & 83.1 & 100 & 100 & 63.2 & $79.2 \%-86.6 \%$ \\
\hline $\mathrm{nMPCR}$ & $\begin{array}{l}\text { Positive } \\
\text { Negative }\end{array}$ & $\begin{array}{l}403 \\
12\end{array}$ & $\begin{array}{l}0 \\
120\end{array}$ & 97.1 & 100 & 100 & 90.9 & $95.0 \%-98.5 \%$ \\
\hline CRS & $\begin{array}{l}\text { Positive } \\
\text { Negative }\end{array}$ & $\begin{array}{l}415 \\
0\end{array}$ & $\begin{array}{l}0 \\
120\end{array}$ & 100 & 100 & 100 & 100 & $99.1 \%-100.0 \%$ \\
\hline \multicolumn{9}{|c|}{ Extra-pulmonary TB $(n=65)$} \\
\hline Z-N smear & $\begin{array}{l}\text { Positive } \\
\text { Negative }\end{array}$ & $\begin{array}{l}15 \\
20\end{array}$ & $\begin{array}{l}- \\
30\end{array}$ & 42.9 & 100 & 100 & 60.0 & $26.3 \%-60.6 \%$ \\
\hline Culture & $\begin{array}{l}\text { Positive } \\
\text { Negative }\end{array}$ & $\begin{array}{l}19 \\
16\end{array}$ & $\begin{array}{l}- \\
30\end{array}$ & 54.3 & 100 & 100 & 65.2 & $36.6 \%-71.2 \%$ \\
\hline Single step mPCR & $\begin{array}{l}\text { Positive } \\
\text { Negative }\end{array}$ & $\begin{array}{l}20 \\
15\end{array}$ & 30 & 57.1 & 100 & 100 & 66.7 & $39.3 \%-73.7 \%$ \\
\hline $\mathrm{nMPCR}$ & $\begin{array}{l}\text { Positive } \\
\text { Negative }\end{array}$ & $\begin{array}{l}32 \\
3\end{array}$ & $\begin{array}{l}2 \\
28\end{array}$ & 91.4 & 93.3 & 94.1 & 90.3 & $76.9 \%-98.2 \%$ \\
\hline CRS & $\begin{array}{l}\text { Positive } \\
\text { Negative }\end{array}$ & $\begin{array}{l}35 \\
0\end{array}$ & $\begin{array}{l}0 \\
30\end{array}$ & 100 & 100 & 100 & 100 & $90.0 \%$ to $100.0 \%$ \\
\hline
\end{tabular}

PPV positive predictive value, NPV negative predictive value, TB group TB suspected patients, $m P C R$ multiplex $P C R, n M P C R$ nested multiplex $P C R, C R S$ composite reference standard 
DNA [33] and may also be due to selection of multiple target sequences included MTP40, IS6110 and $32 k D-\alpha$ antigen encoding gene in a two step reaction.

The sensitivity of nMPCR was observed to be $97.1 \%$ and $91.4 \%$ with CRS criteria for pulmonary and extrapulmonary samples respectively which was greater than $80.2 \%$ [17] and $91 \%$ [18] sensitivity reported in the previous studies using multiplex PCR and nested PCR respectively. Specificity of nMPCR assay was observed to be $100 \%$ and $93.9 \%$ respectively for pulmonary and extra-pulmonary TB cases with CRS criteria which were comparable with that of $94.4 \%$ [17] and $91 \%$ [18] reported in the previous studies. In this study we have used more than two targets in nested multiplex PCR protocol due to which sensitivity increased from 83.1 to $97.1 \%$ for pulmonary and from 57.1 to $91.4 \%$ for the EPTB diagnosis. In group D two specimens were considered as false negative by CRS criteria but using nMPCR assay it becomes positive. Therefore specificity was found to be $93.3 \%$ for nMPCR assay in extrapulmonary TB cases.

The low sensitivity of culture $(79.3 \%$ and $54.3 \%)$ and single step mPCR assay ( $83.1 \%$ and $57.1 \%)$ for PTB and EPTB cases in comparison with that of nMPCR test $(97.1 \%$ and $91.4 \%)$ may be due to the fact that $86 \%$ $(88 / 102)$ of the culture negative, nMPCR positive patients were on ATT for various time periods; unequal distribution of mycobacteria in paucibacillary respiratory specimens, low number of bacterial load in extrapulmonary specimens and non-uniform dispersion of microorganisms in clinical specimens causes clumping of the microorganisms which is the most common problem with mycobacteria [34, 35]. Moreover, nMPCR can detect a single bacillus present in clinical specimens than culture and single step mPCR $[33,36]$.

The limitation with nMPCR assay is that it is not able to differentiate live from dead organisms. Hence, this method should be recommended only for screening of new cases but not for monitoring of patients in treatment. Liquid culture (MIGIT 960) could have increased the sensitivity as it is known to be $10 \%$ more sensitive [37]. Also using $4 \% \mathrm{NaOH}$ for decontamination is a limitation of this study as it is known to be a harsh decontaminant. The advantage of nested multiplex PCR is that it improves the sensitivity and specificity using signature nucleotides for the detection and differentiation of MTBC from NTM in clinical specimens that were even smear and culture negative. To the best of our knowledge, although nested multiplex PCR assay has been used for the diagnosis of pulmonary TB, there is only one report of it being used for EPTB cases [38]. It is obvious that further evaluation is needed in order to improve this nested multiplex PCR protocol for routine diagnosis.

\section{Conclusions}

Our study advocates that nested multiplex PCR is a highly sensitive and specific technique for the diagnosis of pulmonary and extra-pulmonary TB which is often not only missed by conventional methods but also by single-step multiplex PCR due to low bacillary load, resulting in an unacceptable delay in initiation of therapy. Further, it can also be used to detect samples with $M$. tuberculosis strains lacking IS6110. This study also concludes that the CRS criteria were better for assessing the diagnostic accuracy of nested multiplex PCR assay.

\section{Additional file}

Additional file 1: Comparison of conventional procedures with singlestep \& nested multiplex PCR for detection of M. tuberculosis complex in different groups of patients. (DOCX $15 \mathrm{~kb}$ )

\section{Abbreviations}

AFB: acid fast bacilli; ATT: anti-tubercular therapy; BAL: bronchoalveolar Lavage; CRS: composite reference standard; CSF: cerebrospinal fluid; EPTB: extra-pulmonary tuberculosis; FNAC: fine needle aspirate cytology; FNAs: fine needle aspirates; $\amalg$ : lowenstein jensen; mPCR: multiplex PCR; MTB: Mycobacterium tuberculosis; MTBC: Mycobacterium tuberculosis complex; NAAT: nucleic acid amplification technique; nMPCR: nested multiplex PCR; nPCR: nested polymerase chain reaction; NTM: nontuberculous mycobacteria; PCR: polymerase chain reaction; PTB: pulmonary tuberculosis; S + C-: smear positive culture negative; $\mathrm{S}+\mathrm{C}+$ : AFB smear positive and culture positive; $\mathrm{S}-\mathrm{C}-$ : smear negative and culture negative; $\mathrm{S}-\mathrm{C}+$ : smear negative and culture positive

\section{Competing interests}

The authors declare that they have no competing interests.

\section{Authors' Contributions}

PS, AG, PP, RT, SA, GNS have made substantial contributions to conception and design, or acquisition of data, or analysis and interpretation of data; PS, AG, SA have been involved in drafting the manuscript or revising it critically for important intellectual content; and PS, AG, SA, PP, GNS, RT have given final approval of the version to be published.

\section{Acknowledgment}

We would like to express our sincere gratitude and appreciation to the Head, Department of Microbiology, IMS and to the patients, staff and managements of the Sir Suderlal Hospital, Banaras Hindu University, Varanasi and Dr. Gyan Prakash Singh for helping in statistical analysis.

\section{Funding}

This study was financially supported by Department of Science and Technology, New Delhi (Grant No. DST/INSPIRE Fellowship/2011). The funders had no role in study design, data collection and analysis, decision to publish, or preparation of the manuscript.

\section{Author details}

${ }^{1}$ Department of Microbiology, Institute of Medical Sciences, Banaras Hindu University, 221005 Varanasi, India. ${ }^{2}$ Departmrnt of TB and Respiratory Diseases, Institute of Medical Sciences, Banaras Hindu University, Varanasi, India.

Received: 9 October 2015 Accepted: 1 March 2016

Published online: 12 March 2016

\section{References}

1. World Health Organization. Global tuberculosis report. Geneva, Switzerland: WHO Press; 2014. http://www.who.int/tb/publications/global_report/en. 
2. Alexander KA, Laver PN, Michel AL, et al. Novel Mycobacterium tuberculosis Complex Pathogen. M mungi Emerg Infect Dis. 2010;16:1296-9.

3. Watterson SA, Wilson M, Yates MD, Drobniewski FA. Comparison of three molecular assays for a rapid detection of rifampin resistance in Mycobacterium tuberculosis. J Clin Microbiol. 1998;36:1969-73.

4. Wolinsky E. Mycobacterial diseases other than tuberculosis. Clin Infect Dis. 1992;15:1-10.

5. Gopinath K, Singh S. Non-Tuberculous Mycobacteria in TB-Endemic Countries: Are We Neglecting the Danger? PLoS Negl Trop Dis. 2010;4(4): e615. doi:10.1371/journal.pntd.0000615.

6. Kimerling ME, Schuchter J, Chanthol E, Kunthy T, Stuer F, Glaziou P, et al. Prevalence of pulmonary tuberculosis among HIV-infected persons in a home care program in Phnom Penh, Cambodia. Int J Tub Lung Dis. 2002;6:988-94.

7. Aliyu G, El-Kamary SS, Abimiku A, Brown C, Tracy K, Hungerford L, et al. Prevalence of Non-Tuberculous Mycobacterial Infections among Tuberculosis Suspects in Nigeria. PLoS ONE. 2013;8(5):e63170.

8. Mokaddas E, Ahmad S. Development and evaluation of multiplex PCR for rapid detection and differentiation of Mycobacterium tuberculosis complex members from Non-tuberculous mycobacteria. Jpn J Infect Dis. 2007;60:140-4.

9. Cheng VC, Yam WC, Hung IFN, Woo PC, Lau SK, Tang BS. Clinical evaluation of the polymerase chain reaction for the rapid diagnosis of tuberculosis. J Clin Pathol. 2004;57:281-5.

10. Derese Y, Hailu E, Assefa T, Bekele Y, Mihret A, Aseffa A, et al. Comparison of PCR with standard culture of fine needle aspiration samples in the diagnosis of tuberculosis lymphadenitis. J Infect Dev Ctries. 2012;6:53-7.

11. Kathirvel M, Kommoju V, Brammacharry U, Ravibalan T, Ravishankar N, Radhakrishnan B, et al. Clinical evaluation of $\mathrm{mtp} 40$ polymerase chain reaction for the diagnosis of extra pulmonary tuberculosis. World J Microbiol Biotechnol. 2014;30:1485-90.

12. Shukla I, Varshney S, Malik AS, Ahmad Z. Evaluation of nested PCR targeting IS6110 of Mycobacterium tuberculosis for the diagnosis of pulmonary and extra-pulmonary tuberculosis. Biol Med. 2011;3(2):171-5.

13. Perkins M, Roscigno G, Zumla A. Progress towards improved tuberculosis diagnostics for developing countries. Lancet. 2006;367:942-3.

14. Styrt BA, Shinnick TM, Ridderhof JC, Crawford JT, Tenover FC. Turnaround times for mycobacterial cultures. J Clin Microbiol. 1997;35:1041-2.

15. Herrera EA, Segovia M. Evaluation of mtp40 Genomic Fragment Amplification for Specific Detection of Mycobacterium tuberculosis in Clinical Specimens. J Clin Microbiol. 1996;34(5):1108-13.

16. Therese $\mathrm{KL}$, Jayanthi $\mathrm{U}$, Madhavan $\mathrm{HN}$. Application of nested polymerase chain reaction ( $\mathrm{nPCR}$ ) using MPB 64 gene primers to detect Mycobacterium tuberculosis DNA in clinical specimens from extrapulmonary tuberculosis patients. Ind J Med Res. 2005;122:165-70.

17. Deshmukh M, Nikam C, Ragte T, Shetty A, Rodrigues C. Is a composite reference standard (CRS) an alternative to culture in assessment and validation of a single tube nested in-house PCR for TB diagnosis from extrapulmonary tuberculosis patients. Ind J Med Res. 2005;122:165-70.

18. Nikam C, Jagannath M, Narayanan MM, Ramanabhiraman V, Kazi M, Shetty A, Rodrigues C. Rapid Diagnosis of Mycobacterium tuberculosis with Truenat MTB: A Near-Care Approach. PLOS ONE. 2013;8(1):e51121. doi:10.1371/journal.pone. 0051121.

19. Vadwai V, Boehme C, Nabeta P, Shetty A, Alland D, Rodrigues C. Xpert MTB/ RIF: a new pillar in diagnosis of extrapulmonary tuberculosis? J Clin Microbiol. 2011;49(7):2540-5.

20. Kent PT, Kubica GPW. Public Health Mycobacteriology. A guide for the level III Laboratory. Atlanta: Centers for Disease Control; 1985. p. 21-44.

21. Roberts GD. Mycobacteria and Norcardia. In: Washington II JA, editor. Laboratory procedures in clinical microbiology. New York: Springer Verlag; 1981. p. 365-406.

22. Siddiqi SH, Rüsch-Gerdes S. MGIT Tm Procedure Mannual. 2006.

23. Revised National Tuberculosis Control Programme (RNTCP). Manual for laboratory technician. New Delhi: Central TB Division, Directorate General of Health Services, Ministry of Health and Family Welfare 2120; 2010.

24. Canetti G, Rist N, Grosset J. Measurement of sensitivity of the tuberculous bacillus to antibacillary drugs by the method of proportions. Rev Tuberc Pneumol. 1963:27:217-72.

25. Kubica GP. Differential identification of mycobacteria. VII. key to features for identification of clinically significant mycobacteria. Am Rev Respir Dis. 1973; 107:9-21.
26. Van Embden JDA, Cave MD, Crawford JT. Strain identification of Mycobacterium tuberculosis by DNA fingerprinting: Recommendations for a standardized methodology. J Clin Microbiol. 1993;31:406-9.

27. Portillo DP, Thomas MC, Martínez E, Marañón C, Valladares B, Patarroyo ME, et al. Multiprimer PCR system for differential identification of mycobacteria in clinical samples. J Clin Microbiol. 1996;34(2):324.

28. Singh KK, Muralidhar M, Kumar A, Chattopadhyaya TK, Kapila K, Singh MK, et al. Comparison of in house polymerase chain reaction with conventional techniques for the detection of Mycobacterium tuberculosis DNA in granulomatous lymphadenopathy. J Clin Pathol. 2000;53:355-61.

29. Cruz HLA, Montenegro RA, Lima JFA, Poroca DR, Lima JFC, Montenegro LML, et al. Evaluation of a Nested-Pcr for Mycobacterium tuberculosis Detection in Blood and Urine Samples. Braz J Microbiol. 2011:42(1):321-9.

30. Negi SS, Anand R, Pasha ST, Gupta S, Basir SF, Khare S, et al. Diagnostic potential of IS6110, 38KDa, and 85B sequence based polymerase chain reaction in the diagnosis of $M$. tuberculosis in clinical samples. Ind J Med Microbiol. 2007;25:43-9.

31. Chauhan DS, Sharma VD, Parashar D, Chauhan A, Singh D, Singh HB, et al. Molecular typing of Mycobacterium tuberculosis isolates from different parts of India based on IS6110 element polymorphism using RFLP analysis. I J Med Res. 2007;125:577-81.

32. Barani R, Sarangan G, Antony T, Periyasamy S, Kindo AJ, Srikanth P. Improved detection of Mycobacterium tuberculosis using two independent PCR targets in a tertiary care centre in South India. J Infect Dev Ctries. 2012; 6(1):46-52.

33. Mishra A, Singhal A, Chauhan DS, Katoch VM, Srivastava K, Thakral SS, et al. Direct Detection and Identification of Mycobacterium tuberculosis and Mycobacterium bovis in Bovine Samples by a Novel Nested PCR Assay: Correlation with Conventional Techniques. J Clin Microbiol. 2005;43:5670-8.

34. Beige J, Lokies J, Schaberg T, Finckh U, Fischer M, et al. Clinical evaluation of a Mycobacterium tuberculosis PCR assay. J Clin Microbiol. 1995;33:90-5.

35. Clarridge III JE, Shawar RM, Shinnick TM, Plikaytis BB. Large-scale use of polymerase chain reaction for detection of Mycobacterium tuberculosis in a routine mycobacteriology laboratory. J Clin Microbiol. 1993;31:2049-56.

36. Madhavan HN, Therese KL, Gunisha P, Jayanthi U, Biswas J. Polymerase chain reaction for detection of Mycobacterium tuberculosis in epiretinal membrane in Eales' disease. Invest Ophthalmol Vis Sci. 2000:4:822-5.

37. Cruciani M, Scarparo C, Malena M, Bosco O, Serpelloni G, Mengoli C. Metaanalysis of BACTEC MGIT 960 and BACTEC 460 TB, with or without solid media, for detection of mycobacteria. J Clin Microbiol. 2004;42(5):2321-5.

38. García-Elorriaga G, Martínez-Elizondo O, Rey-Pineda G, González-Bonilla C. Clinical, radiological and molecular diagnosis correlation in serum samples from patients with osteoarticular tuberculosis. Asian Pac J Trop Biomed. 2014:4(7):581-5.

39. Wojciech R. Oligoe Version 4.0. Plymouth, Minn.: National Biosciences, Inc:; 1992.

40. Ohara N, Matsuo K, Yamaguchi R, Yamasaki A, Tasaka H, Yamada T. Cloning and sequencing of the gene for the alpha antigen from Mycobacterium avium and mapping of B cell epitopes. Infect. Immun. 1993;61:1173-1179.

\section{Submit your next manuscript to BioMed Central and we will help you at every step:}

- We accept pre-submission inquiries

- Our selector tool helps you to find the most relevant journal

- We provide round the clock customer support

- Convenient online submission

- Thorough peer review

- Inclusion in PubMed and all major indexing services

- Maximum visibility for your research

Submit your manuscript at www.biomedcentral.com/submit 